\title{
Application of the Kushida morphometric model in patients with sleep-disordered breathing
}

\section{Maria Claudia Mattos Soares', Lia Rita de Azeredo Bittencourt $^{2}$, Adriane Iurck Zonato ${ }^{3}$, Luis Carlos Gregório ${ }^{4}$}

Keywords: obstrutive sleep apnea, mouth, measurements, obesity.

\section{Summary}

T he morphometric model is a useful screening test to investigate the possibility of OSAS in patients during initial office visits. Aim: To evaluate the clinical applicability of the Kushida morphometric model in a sample of patients with sleep-disordered breathing, and to define a cutoff value to differentiate patients with mild, moderate and severe apnea. Method: A sample of 80 patients with sleep respisratory disorder was studied. Patients were aged between 18 and 75 years, of both genders and had been submitted previously to polysomnography. The model cutoff value to distinguish between patients with or without apnea is 70. Results: In this sample, the model cutoff value in all four groups was less than 70. It was impossible to establish a cutoff value according to the gravity of the condition, due to the proximity and the nonlinear increase in the values presented by the nonapneic group and those with mild and moderate apnea. Conclusion: The Kushida morphometric model can be applied in clinical practice to a selected sample and it was impossible to establish a cutoff value to separate patients with obstructive sleep apnea-hypopnea syndrome according to severity.

\footnotetext{
${ }^{1}$ Otorhinolaryngologist and sleep medicine specialist, Master's degree graduate student at UNIFESP, collaborating physician of the otorhinolaryngology unit at FMABC. ${ }^{2}$ Doctor in Medicine, Pneumologist and sleep medicine specialist.

${ }^{3}$ Doctor in Medicine, Otorhinolaryngologist and sleep medicine specialist.

${ }^{4}$ Doctor in Medicine, Head of the Otorhinolaryngology and Head \& Neck Surgery Unit - UNIFESP. Sao Paulo Federal University.

Address for correspondence: Maria Claudia Mattos Soares - R. Prof. Zoraide de Campos Helú 4 Ipiranga São Paulo SP 04265-020. Capes.

Paper submitted to the ABORL-CCF SGP (Management Publications System) on February 7th, 2006 and accepted for publication on May 30 th, 2006.
} 


\section{INTRODUCTION}

Studies of the main characteristics of patients with Sleep Apnea-Hypopnea Syndrome (SAHS) started with Burwell, Robin, Waley and Bickelmann (1956)1. They described the Pickwickian Syndrome to honor the English novelist Charles Dickens, author of the famous "The Posthumous Papers of the Pickwickian Club" (1837), the main character of which was an obese, sleepy and snoring boy. The syndrome is classically composed of obesity, hypercapnia, cor pulmonale, erythrocytosis and excessive daytime sleepiness.

According to the definition published by the American Academy of Sleep Medicine (AASM) during a task force launched in 1999, SAHS is characterized by recurring episodes of partial or total obstruction of upper airways during sleep. It presents as a reduction (hypopnea) or cessation (apnea) of air flow, regardless of inspiratory effort, lasting at least 10 seconds. Hypopnea is defined as a more than $50 \%$ reduction in respiratory amplitude, or less than 50\% if associated with oxygen desaturation over 3\% and/or awakening (AASM Task Force, 1999)².

In an important epidemiological study, Young, Palta, Dempsey, Skatrud, Weber and Badr $(1993)^{3}$ concluded that SAHS has an increased prevalence in the obese, affecting $2 \%$ of women and $4 \%$ of men if we consider an apnea-hypopnea index (AHI) over 5 on polysomnography (PSG) and the presence of excessive daytime sleepiness; this condition is more frequent in middle-aged persons (Olson, King, Hensley and Saunders, 1995) .

The pathophysiology of SAHS is still not fully understood; it is clear that the main phenomenon of the disease is pharyngeal collapse resulting in part from upper airway and facial skeletal anatomical alterations and reduced neuromuscular tonus (Arens and Marcus, 2004)5.

The main SAHS-related upper airway anatomical alterations are: tonsillar hypertrophy, a large tongue, medial tonsillary pillars, a posterior and/or thickened and/or a web (a membrane formed by the low insertion of the tonsillar pillar posterior to the uvula) soft palate, and a long and/or thickened uvula ${ }^{6-9}$.

Many studies have been done assessing craniofacial dimorphism in SAHS patients using cephalometrics, computed tomography, magnetic resonance imaging, and acoustic reflection. Although there is controversy in the results, craniofacial alterations most closely related to the occurrence and severity of SAHS are: retroposition of the maxilla, shortening of the mandibular body, inferiorly displaced hyoid bone, retrognatism, dental occlusion class II (mesial sulcus of the 1st permanent lower molar articulates posteriorly with the mesiovestibular cusp of the 1st permanent upper molar) and ogival hard palate $e^{5,7-12}$.

Currently SAHS is considered a chronic, progressive and incapacitating disease with high morbidity and mortality, since it is associated with an increased risk of cardiovascular diseases, traffic accidents and depression. It is considered a public health issue $e^{13-16}$.

PSG is an essential assessment and diagnosis tool in Sleep Medicine; however, it is a time-consuming and expensive exam requiring expert technicians, which frequently limits its use, with the result that SAHS is underdiagnosed. Young, Evans, Finn and Palta $(1997)^{17}$ estimated that $93 \%$ of women and $82 \%$ of men with moderate or severe SAHS are not diagnosed by physicians.

Various investigators have developed predictive clinical rules for SAHS using mathematical formulae including variables such as the body mass index (BMI), the cervical circumference (CC), oxygen saturation, the $\mathrm{AHI}$ and questionnaires ${ }^{6,7,18-21}$. However, these models do not take into account craniofacial alterations, and some authors consider them insufficient ${ }^{22}$. Kushida, Efron and Guilleminault (1997) ${ }^{22}$ proposed a morphometric model (MM) described below, which includes measurements of the mouth, the BMI and the CC to predict which patients would be at an increased risk for SAHS (and therefore would require PSG promptly). This model was applied to 300 patients (224 men and 76 women) aged between 15 and 75 years. All of them had undertaken PSG, but the examiner did not have access to the results of this exam. The criteria for diagnosing SAHS was the presence of typical symptoms (snoring, respiratory pauses, excessive daytime sleepiness, Epworth's Sleepiness Scale $>10$, and an $\mathrm{AHI}>5$.

$$
\{\mathrm{P}+(\mathrm{Mx}-\mathrm{Mn})+3 \mathrm{x} \mathrm{OJ}\}+3 \mathrm{x}[\mathrm{Max}(\mathrm{IMC}-25)] \mathrm{x}
$$

(CC / IMC)

P: palatal height in millimeters

Mx: distance between the mesial side of the upper 2nd molars in millimeters

Mn: distance between the mesial side of the lower inferior 2nd molars in millimeters

OJ: overjet (horizontal distance between the incisor side of the upper and lower central incisors)

BMI: weight (kilograms)/height (meter2)

CC: cervical circumference in centimeters

In patients with a BMI $\leq 25$ only the first part of the formula was applied (between wavy brackets) in such a way that the second part of the formula (between brackets) was always zero or a positive number.

Following application of the MM, patients were divided into two groups: one without SAHS $(M M<70)$ and one with SAHS (MM $\geq 70) ; 46$ patients were allocated to the first group and 254 to the second group. The MM classified six patients with SAHS as non-apneic. Sensitivity was $97 \%$, specificity was $100 \%$, the positive predictive value was $100 \%$, and the negative predictive value was $88.5 \%$.

The BMI and the CC were also used to divide the 
patients into both groups, with cutoff points of $25 \mathrm{~kg} / \mathrm{m} 2$ (BMI) and $40 \mathrm{~cm}$ (CC). We compared the individual capability of the MM, the BMI and the CC to identify patients with and without SAHS; the MM was superior, followed by the BMI and the CC.

The authors conclude that the MM is a quick and safe form of screening patients that will require specialized investigation such as PSG to establish the severity of the disease and to guide the appropriate treatment.

The aims of this study were to assess the clinical applicability of the Kushida MM in a sample of patients with sleep-related respiratory disorders (SRDs) and to define a cutoff point to identify patients with mild, moderate and severe apnea.

\section{METHODS}

We studied 80 patients from the Sleep Disorders Outpatient Clinic of the Otorhinolaryngology (ORL) and Head \& Neck Surgery (HNS) Unit at the Sleep Institute of the Sao Paulo Federal University (UNIFESP) between September 2003 and August 2004. All patients underwent prior polysomnography and accepted the free and informed consent form proposed. The study was approved by the UNIFESP-EPM Research Ethics Committee.

\section{Inclusion criteria}

- patients complaining of snoring, apnea and/or excessive daytime sleepiness

- adults aged between 18 and 75 years

- both genders raphy.

- patients having undertaken a prior polysomnog-

\section{Exclusion criteria} neoplasms

- a history of benign or malignant upper airway

- patients with limited mouth opening

- absence of upper and/or lower central incisors

- absence of the upper and lower 2nd molars

- patients unable or unwilling to cooperate with the study

- prior treatment for SAHS

- the use of illegal drugs, alcohol and hypnotic medication.

\section{Selection of patients}

The 80 patients were selected from the sleep Disorders Outpatient Clinic of the ORL and HNS Unit at UNIFESP during consultation with an otorhinolaryngologist or when undergoing PSG. There were 20 patients with mild SAHS $(5>$ AHI $\leq 15), 20$ patients with moderate SAHS $(15>\mathrm{AHI} \leq 30), 20$ patients with severe SAHS (AHI >30 and 20 patients with a normal AHI (AHI $\leq 5)$.

\section{Polysomnography}

Polysomnography was an overnight recording of the patients sleep with monitoring by an electroencephalogram (EEG), an electrooculogram (EOG), a tibialis and mentalis electromyogram (EMG), an electrocardiogram (ECG), measurement of airflow through a nasal cannula and an oral thermistor, breathing movements measured by thoracoabdominal belt, oxymetry for $\mathrm{SaO} 2$, and microphone recordings of snoring. We used the SAC-Oxford, version 10.0 polysomnograph.

EEG, EOG and EMG interpretation defined sleep architecture stages according to the criteria proposed by Rechtschtaffen and Kales (1968).

The staging of respiratory events followed the criteria proposed by the AASM (AASM Task Force, 1999).

\section{Assessment of patients}

After selection, age, gender, weight, height, and frequency of snoring (nightly, nearly every night, occasionally or never) were recorded. Patients with an AHI $\leq$ 5 , but which reported snoring every night or nearly every night, were classified as snorers. Patients that snored occasionally or never were classified as non-snorers if PSG recorded intermittent snoring; if PSG recorded constant snoring, these patients were classified as snorers.

Next, Kushida's MM was applied. Patients were placed in the Frankfurt position and standard tools were used; all measurements were made by the same examiner. Measurements of the mouth, except for overjet (OJ), were made with the tongue in a relaxed position and the mouth open at a $20^{\circ}$ angle with the mandibular condyle. A compass with a fixed $20^{\circ}$ angle was placed over the temporomandibular joint; the tip of the upper leg was aligned with the upper central incisors and the tip of the lower leg was aligned with the lower central incisors, thus obtaining the desired mouth opening. A second compass was used to obtain the mouth measurements (the maxilla intermolar distance - $\mathrm{Mx}$, the mandible intermolar distance - Mn and the palatal height - P), which were then transposed to a ruler. A 40 millimeter $(\mathrm{mm})$ ruler was used to measure the OJ, and a tape measure was placed over the cricothyroid membrane to measure the CC.

\section{Forms of assessing the results}

Variables were expressed as the average, the standard deviation, and minimum and maximum values, which showed a normal distribution.

ANOVA was used for comparison between groups; Ducan's post-test was used if needed to separate the groups.

The Student's T test for independent samples was used for comparisons between two groups.

Peason's test was used to assess correlations between variables. 
The multivariate regression analysis was used to assess factors that could define the weighting of some measurements.

\section{RESULTS}

Ages and the BMI of the 80 patients are shown on Table 1. There were more men than women ( $54 \mathrm{men} / 26$ women); the average age was $40.5 \pm 13.6$ years, and on average the patients were slightly overweight.

Data on orofacial and CC measurements and final MM values of the 80 patients are on Table 2 .

A comparison between the averages of all variables for the four groups in this study is shown on Table 3. The following variables were significant in the comparison of the four groups of patients ( $\mathrm{p} \leq 0.05$ ): age, BMI, E1 and 2, SaO2 min, OJ, CC and MM. The following variables were not significant ( $\mathrm{p}>0.05$ ): ES, E3 and 4, REM, P, Mx and Mn.

Variables were compared according to gender and whether snoring was present or absent; differences are shown on Tables 4 and 5 . Variables that were statistically

Table 3. Average and standard deviation of variables in subgroups.
Table 1. Age and BMI of the 80 patients.

\begin{tabular}{lcc}
\hline Variables & Age (years) & BMI $(\mathrm{Kg} / \mathrm{m} 2)$ \\
\hline Average & 40,5 & 27,4 \\
Standard Deviation & 13,6 & 4,9 \\
Minimum Value & 18,0 & 17,0 \\
Maximum Value & 71,0 & 45,0 \\
\hline
\end{tabular}

BMI: body mass index

Table 2. Orofacial and Cervical Circumference Measurements and Morphometric Model Values of the 80 patients.

\begin{tabular}{lcccccc}
\hline Variables & $\mathrm{P}$ & $\mathrm{Mx}$ & $\mathrm{Mn}$ & $\mathrm{OJ}$ & $\mathrm{CC}$ & $\mathrm{MM}$ \\
\hline Average & 31,3 & 37,2 & 36,4 & 3,23 & 40,4 & 55,1 \\
Standard Deviation & 6,3 & 4,5 & 6,1 & 2,65 & 4,1 & 18,1 \\
Minimum Value & 20,0 & 27,0 & 4,0 & 0,0 & 31,0 & 26,0 \\
Maximum Value & 48,0 & 51,0 & 46,0 & 20,0 & 54,0 & 115,5
\end{tabular}

P: palatal height in millimeters

Mx: distance between the mesial side of the upper 2 nd molars millimeters

$\mathrm{Mn}$ : distance between the mesial side of the lower 2nd molars millimeters

OJ: overjet in millimeters

CC: cervical circumference in centimeters

MM: morphometric model values

\begin{tabular}{|c|c|c|c|c|c|c|c|c|c|}
\hline \multirow[t]{2}{*}{ Variables } & Non-apneic & \multirow[t]{2}{*}{ SD } & Mild SAHS & \multirow[t]{2}{*}{ SD } & \multirow{2}{*}{$\begin{array}{c}\text { Moderate SAHS } \\
n=20\end{array}$} & \multirow[t]{2}{*}{ SD } & \multirow{2}{*}{$\begin{array}{c}\text { Severe SAHS } \\
n=20\end{array}$} & \multirow[t]{2}{*}{ SD } & \multirow[t]{2}{*}{$\mathrm{p}$} \\
\hline & $n=20$ & & $\mathrm{n}=20$ & & & & & & \\
\hline Age (years) & 35,2 & 13,3 & 37,9 & $15,9 *$ & 47,2 & $11,9 \bullet *$ & 41,2 & 10,6 & 0,027 \\
\hline Gender (M/F) & $5 / 15$ & & $15 / 5$ & & $18 / 2$ & & $16 / 4$ & & \\
\hline $\mathrm{BMI}$ & 25,5 & $5,7 \square$ & 25,5 & $2,7 \square$ & 27,3 & $3,2^{*}$ & 31,4 & $5^{\star} \square$ & 0,0001 \\
\hline ES & 81,5 & 11,3 & 80,7 & 12,8 & 82,6 & 14 & 83,2 & 9,9 & 0,920 \\
\hline $\mathrm{E} 1$ e 2 & 63,4 & $7,5 \square$ & 62,9 & $10 \square$ & 65,5 & 8,7ロ & 78,3 & $9,2 \square$ & 0,000001 \\
\hline E3 e 4 & 20,3 & 6,4 & 19,4 & 8,7 & 15,2 & 7,17 & 21,6 & 24,7 & 0,506 \\
\hline REM & 16,7 & 6,6 & 17,9 & 5,9 & 19,7 & 6,2 & 16,7 & 6,8 & 0,132 \\
\hline $\mathrm{SaO} 2 \mathrm{~min}$ & 89,6 & $2,9 \square$ & 86,3 & $5 \square$ & 77,9 & 8,8 & 67,2 & $10,8 \square$ & 0,000000 \\
\hline $\mathrm{P}$ & 31,6 & 7,1 & 31 & 5,6 & 33,3 & 4,3 & 29,2 & 7,5 & 0,230 \\
\hline $\mathrm{Mx}$ & 39,2 & 4,6 & 36,3 & 4,4 & 36,7 & 4,8 & 36,6 & 4 & 0,152 \\
\hline $\mathrm{Mn}$ & 34,8 & 8,5 & 36,7 & 5 & 37,9 & 5,1 & 36,2 & $5,1 \bullet$ & 0,444 \\
\hline OJ & 2,9 & 1,3 & 3,7 & 2,1 & 2,61 & 1,8 & 3,6 & 4,4 & 0,41 \\
\hline $\mathrm{CC}$ & 36,7 & $3,7^{\star} \square$ & 40,3 & $3,1^{*}$ & 41,2 & $2,2 \bullet \square$ & 43,6 & $3,9 \bullet$ * & 0,000000 \\
\hline MM & 52,4 & 14,5 & 50,3 & $17^{*}$ & 51,7 & $14,7 \bullet$ & 66,7 & $22,3 \bullet$ * & 0,013 \\
\hline
\end{tabular}

Analysis of Variance ANOVA; Duncan's Post-Test

- $p<0.05$ REM: REM sleep as a percentage

* $p<0.01 \mathrm{SaO} 2 \mathrm{~min}$ : minimum oxyhemoglobin saturation as a percentage

$\square \mathrm{p}<0.001 \mathrm{AHI}$ : apnea-hypopnea index per hour of sleep

$\mathrm{n}$ : number of patients; $\mathrm{P}$ : palatal height in millimeters

DP: standard deviation Mx: distance between the mesial side of the upper 2nd molars millimeters

M: male; Mn: distance between the mesial side of the lower 2nd molars millimeters

$\mathrm{F}$ : female; OJ: overjet in millimeters

SAHS: obstructive sleep apnea-hypopnea syndrome; CC: cervical circumference in centimeter

BMI: body mass index in $\mathrm{Kg} / \mathrm{m} 2$; MM: morphometric model values

ES: sleep efficiency as a percentage

E1 and 2: sum of NREM sleep stages 1 and 2 as a percentage

E3 and 4: sum of NREM sleep stages 3 and 4 as a percentage 
significant regarding gender were: $\mathrm{AHI}, \mathrm{SaO} 2 \mathrm{~min}, \mathrm{Mn}$ and CC. Similar results regarding snoring were: age, BMI, $\mathrm{SaO} 2 \mathrm{~min}, \mathrm{AHI}$ and CC.

When correlating the AHI with the BMI, P, Mx, Mn, OJ, CC and MM, statistically significant variables ( $\mathrm{p} \leq 0.05$ ) were: BMI, CC and MM (Figures 1, 2 and 3). Statistically significant variables were the same for $\mathrm{SaO} 2 \min (\mathrm{p} \leq$ 0.05) (Figures 4, 5 and 6).

The $\mathrm{AHI}$, the $\mathrm{SaO} 2 \mathrm{~min}$, and other variables were analyzed by multivariate linear regression. The CC was significant among them to establish the AHI $(\mathrm{p}=0.03)$. The $\mathrm{Mx}$ was significant $(\mathrm{p}=0.016)$ to establish the $\mathrm{SaO} 2 \mathrm{~min}$.

\section{DISCUSSION}

The average age of the patients was $40.5 \pm 13.6$ years, being higher in the moderate SAHS group. This is similar to reports in literature showing a higher prevalence of the disease between ages 40 and 60. There was a statisti-

Table 4. Average of variables according to gender.

\begin{tabular}{|c|c|c|c|c|c|}
\hline \multirow[b]{2}{*}{ Variables } & \multicolumn{4}{|c|}{ Gender } & \multirow[b]{2}{*}{$p$} \\
\hline & $\begin{array}{c}\text { Male } \\
(n=54 / 67,5 \%)\end{array}$ & SD & $\begin{array}{c}\text { Female } \\
(n=26 / 32,5 \%)\end{array}$ & $\mathrm{SD}$ & \\
\hline $\mathrm{AHI}$ & 29,4 & 27,1 & 13,3 & 21,3 & 0,008 * \\
\hline $\begin{array}{l}\mathrm{SaO} 2 \\
\text { mín }\end{array}$ & 78,1 & 11,4 & 84,7 & 9,8 & 0,013 * \\
\hline $\mathrm{Mn}$ & 37,5 & 5,1 & 34,4 & 7,3 & 0,035 * \\
\hline $\mathrm{CC}$ & 41,9 & 2,6 & 37,5 & 4,8 & $0,000001^{*}$ \\
\hline
\end{tabular}

* Significant findings by the chi-squares test $(p<0.05)$

$\mathrm{n}$ : number of patients

AHI: apnea-hypopnea index by hours of sleep

$\mathrm{SaO} 2$ min: minimum oxyhemoglobin saturation as a percentage $\mathrm{Mn}$ : distance between the mesial side of lower 2 nd molars in millimeters

CC: cervical circumference in centimeters

Table 5. Average of variables according to snoring.

\begin{tabular}{|c|c|c|c|c|c|}
\hline \multirow[b]{2}{*}{ Variables } & \multicolumn{4}{|c|}{ Snoring } & \multirow[b]{2}{*}{$\mathrm{p}$} \\
\hline & $\begin{array}{c}\text { Present } \\
(\mathrm{n}=74 / 92,5 \%)\end{array}$ & $\mathrm{DP}$ & $\begin{array}{c}\text { Absent } \\
(n=6 / 7,5 \%)\end{array}$ & DP & \\
\hline Idade & 41,4 & 13,6 & 28,3 & 6,1 & 0,02 * \\
\hline IMC & 27,8 & 4,7 & 21,8 & 1,9 & 0,003 * \\
\hline $\begin{array}{l}\mathrm{SaO} 2 \\
\text { mín }\end{array}$ & 79,5 & 11,3 & 90,8 & 3,9 & 0,017 * \\
\hline $\mathrm{IAH}$ & 25,7 & 26,6 & 2,7 & 4,1 & 0,038 * \\
\hline $\mathrm{CC}$ & 40,9 & 3,7 & 34,5 & 3,5 & 0,0001 * \\
\hline
\end{tabular}

* Significant findings by the chi-squares test $(p<0.05)$

$\mathrm{n}$ : number of patients

BMI: body mass index

$\mathrm{SaO} 2$ min: minimum oxyhemoglobin saturation as a percentage

AHI: apnea-hypopnea index by hours of sleep

$\mathrm{CC}$ : cervical circumference in centimeters

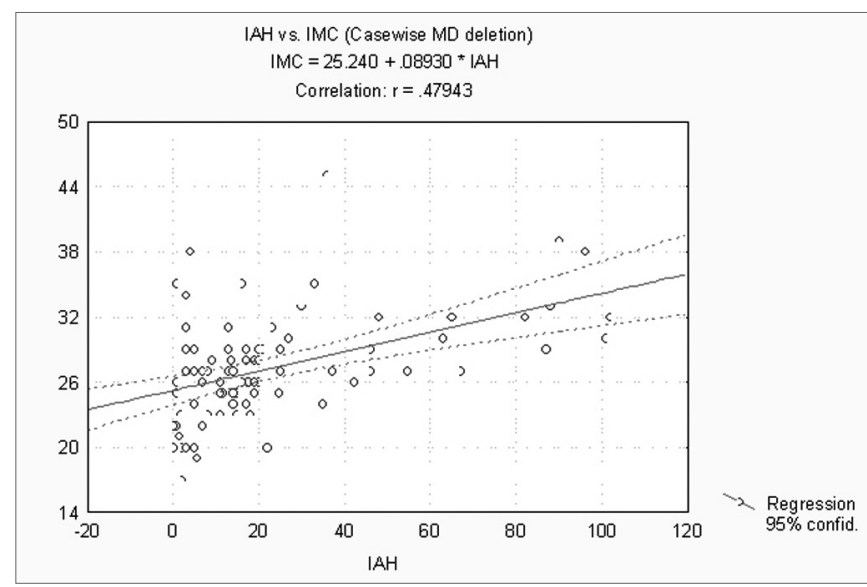

Figure 1. $\mathrm{AHI}$ x BMI - $\mathrm{AHI}$ : apnea-hypopnea index; BMI: body mass index

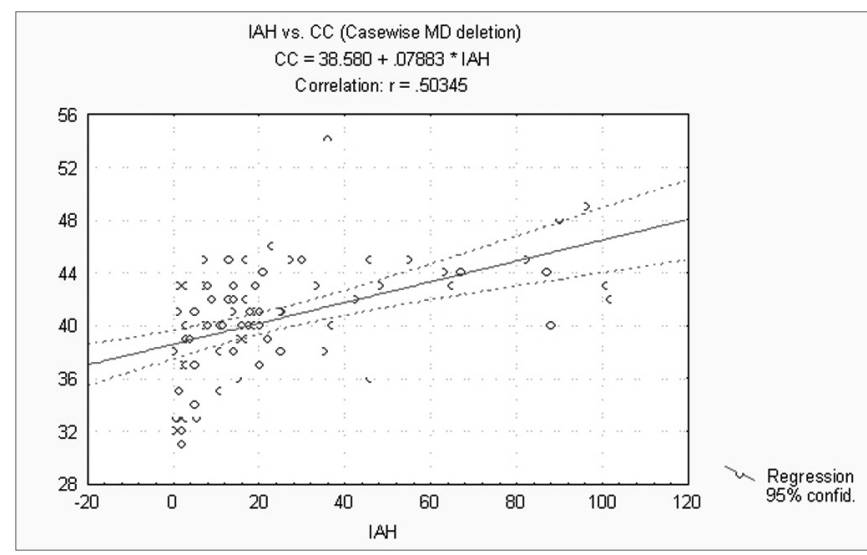

Figure 2. $\mathrm{AHI} \times \mathrm{CC}$ - $\mathrm{AHI}$ : apnea-hypopnea index; $\mathrm{CC}$ : cervical circumference

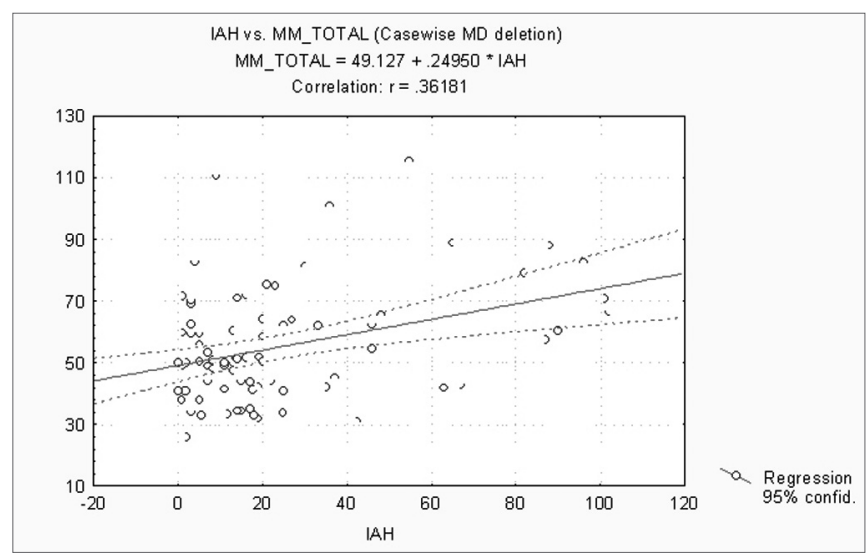

Figure 3. AHI x MM - AHI: apnea-hypopnea index; MM: morphometric model

cally significant difference between the ages of moderate SAHS patients compared to the non-apneic and mild SAHS groups, confirming the increased severity of the disease with age. This is a result of increased muscle flaccidity associated with decreased neuromuscular tonus, making the pharynx prone to collapse and apnea ${ }^{3,4,22}$. 
There were more men than women in an approximately 2:1 proportion. Looking at the groups separately,

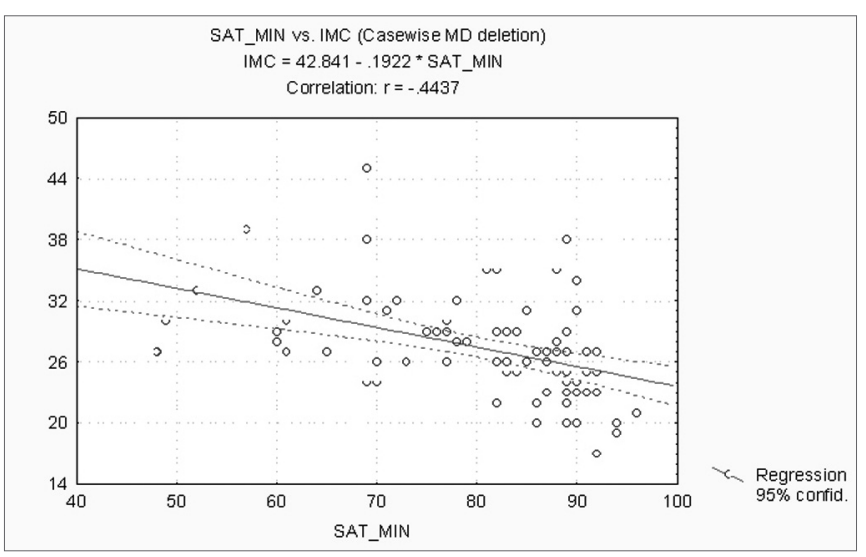

Figure 4. $\mathrm{SaO} 2 \mathrm{~min} \times \mathrm{BMI}-\mathrm{SaO} 2 \mathrm{~min}$ : minimum oxyhemoglobin saturation; $\mathrm{BMI}$ : body mass index

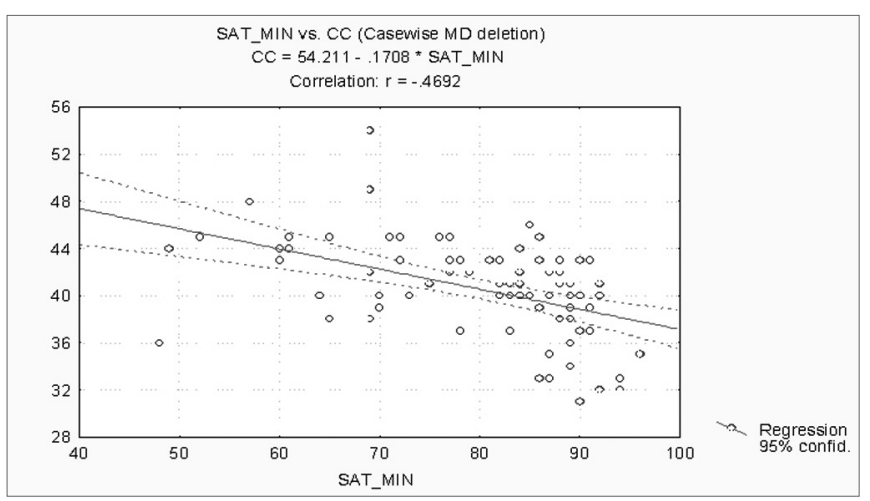

Figure 5. SaO2min x CC - SaO2min: minimum oxyhemoglobin saturation; $\mathrm{CC}$ : cervical circumference

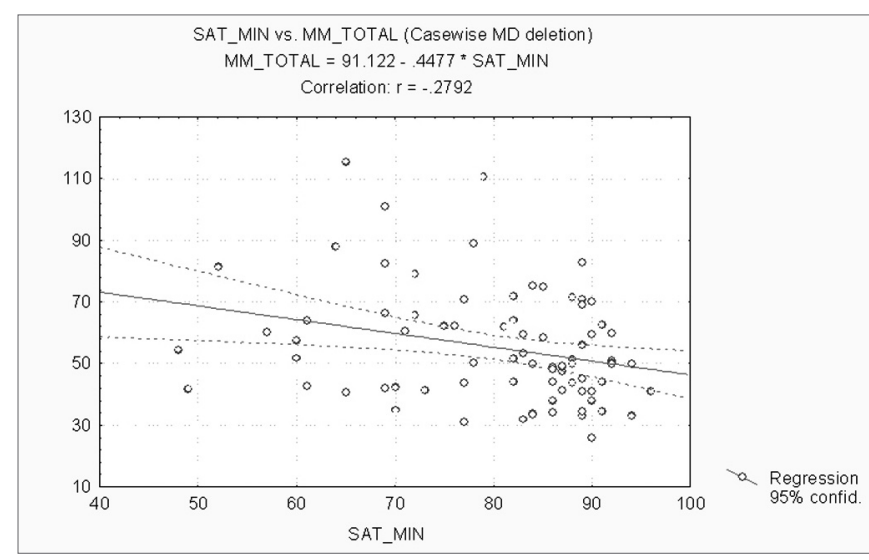

Figure 6. SaO2min x MM - SaO2min: minimum oxyhemoglobin saturation; MM: morphometric model there were more men only in the apnea groups; this is similar to published papers that reveal a greater prevalence of the disease in men ${ }^{3,4}$.

The average BMI was $27.4 \pm 4.9 \mathrm{~kg} / \mathrm{m} 2$, characterizing the group as overweight (BMI between 25 and 29.9 $\mathrm{kg} / \mathrm{m} 2$ ) according to the World Health Organization (1998). The severe SAHS group had statistically significant differences compared to the moderate and mild SAHS groups and the non-apneic group, demonstrating that the BMI is related to the occurrence and severity of the disease $e^{3,6,8}$.

There was a statistically significant difference between groups in the $\mathrm{SaO} 2$ min parameters measured during polysomnography. The pharynx in the SAHS tends to collapse more easily, leading to reduced air flow and a lower $\mathrm{SaO} 2 \mathrm{~min}$; thus, disease severity is proportional to oxyhemoglobin desaturation.

SAHS increases sleep stages 1 and 2, and reduces sleep stages 3 and 4 and REM sleep, as seen on Table 3 . However there was a statistically significant difference between groups only in stages 1 and 2 .

The percentage of slow-wave sleep falls gradually from age 20 onwards. This might explain why the moderate SAHS, which had a higher average age, had a lower percentage of stages 3 and 4 .

There was no statistically significant difference in mouth measurements between our four groups. Mouth measurements (P, Mx and Mn) has lower average values compared to those described by Kushida, Efron and Guilleminault $(1997)^{22}$. In their study, these authors found a statistically significant difference between patients with and without SAHS. These measurements are strongly related to genetic factors and/or to oral breathing. The populations under study in our groups and in Kushida, Efron and Guilleminault's study belong to different origins (Latin and North-Americans), there was no standardization to account for ethnicity, and some of our patients came from the Sleep Disorders Outpatient Clinic of the ORL Unit (which might have led to the selection of a higher number of oral breathers). These facts may explain the differences between both studies.

According to findings by Kushida, Efron and Guilleminault (1997) ${ }^{22}$, and Schellenberg, Maislin and Schwab $(2000)^{8}$, there was a statistically significant difference in measurements of the overjet between subgroups in our sample.

The average cervical circumference was $40.4 \pm 4.1$ $\mathrm{cm}$, and there was a statistically significant difference between the subgroups, with increasing values according to the severity of the obstructive respiratory sleep disorder, confirming published findings that correlate the CC with the occurrence and severity of SAHS ${ }^{19}$. Kushida, Efron and Guilleminault (1997) ${ }^{22}$ established a cutoff point of $40 \mathrm{~cm}$ in CC to separate patients with and without SAHS. In our study the average CC in non-apneic patients was $36.7 \mathrm{~cm}$ 
(31 to $43 \mathrm{~cm}$ ) and the average CC for SAHS patients was over $40 \mathrm{~cm}$, a statistically significant difference coinciding with the values published by the abovementioned authors.

In our study the MM cutoff point was 70 . The values we found were below 70, however the severe SAHS group came closest to this number (66.7 average), a statistically significant difference compared to the other groups. Although there was a significant difference between the subgroups, we were unable to establish a cutoff point according to disease severity, as the values were very similar and did not increase linearly from the non-apneic to the mild and moderate SAHS groups. On the other hand, the authors of the MM state in their paper that, similar to other predictive models, the MM is useful to screen and identify the more severe cases; these patients may then be prioritized for treatment. Furthermore, the authors also underline the importance of PSG as an adequate tool for diagnosis and eventual treatment.

Variables that showed differences when compared according to gender were the $\mathrm{AHI}$, the $\mathrm{SaO} 2 \mathrm{~min}$, the $\mathrm{CC}$ and the $\mathrm{Mn}$, all of them indicating increased severity in men. The male gender is an important risk factor for the occurrence and severity of SAHS ${ }^{2,3,8}$. Thus one would expect that disease-related variables such as the AHI, the $\mathrm{SaO} 2$ min and the CC would have statistically significant values. Furthermore, men tend to accumulate fat in the neck, and the CC provides a better correlation with the presence of SAHS than the body weight ${ }^{19}$. The only mouth measurement that was different between men and women was the Mn $(37.5 \pm 5.1 \mathrm{~cm}$ in men and $34.4 \pm 7.3 \mathrm{~cm}$ in women). After the paper on which our study is based was published, and until our last bibliographical survey, there was no publication reproducing the MM, which restricts comparisons of our data. New studies are needed on this theme so that we may assess the correlation between the new proposed measurements (P, Mx and Mn) and obstructive respiratory sleep disorders.

$92.5 \%$ of patients complained of snoring. Such a high prevalence may be explained by the fact that this is a selected population with obstructive respiratory sleep disorders. Comparing variables according to the presence or absence of snoring, we observed that age, BMI, SaO2 min, AHI and CC had statistically significant differences in both groups, with increased severity in patients with a complaint of snoring. This is expected, as emphasized above concerning the importance of each of these variables in SRD.

Separately correlating the $\mathrm{AHI}$ and the $\mathrm{SaO} 2 \mathrm{~min}$ with the BMI, P, Mx, Mn, OJ, CC and the MM, we found that the statistically significant variables were the BMI, the CC and the MM, for both analyses. The $\mathrm{AHI}$ and the $\mathrm{SaO} 2 \mathrm{~min}$ are strongly linked to SAHS. The variables that best correlate with obstructive respiratory sleep disorders according to medical literature are the BMI and the $\mathrm{CC}^{7,11,18,19,21}$. Our results confirm findings published by these articles.

Individually, measurements of the mouth ( $\mathrm{P}, \mathrm{Mx}$, $\mathrm{Mn}$ and $\mathrm{OJ}$ ) have no statistically significant correlation with the $\mathrm{AHI}$ and the $\mathrm{SaO} 2 \mathrm{~min}$; however, when grouped in the MM, this method shows a strong positive correlation. Calculations in the MM includes measurements of the mouth, the CC and the BMI, which may justify the results and underline the interaction between factors involved in the pathophysiology of SAHS.

Multivariate linear regression analysis revealed that the CC was significant to establish the AHI. This finding, together with the fact that the CC was the only measurement which increased proportionally to the severity of the disease (with a statistically significant difference between all groups), and which correlated with the AHI and the $\mathrm{SaO} 2 \mathrm{~min}$, supports the importance of the relationship between the CC and SAHS, as described previously.

A similar analysis using the $\mathrm{SaO} 2$ min showed that the $\mathrm{Mx}$ is the most significant measurement. The paucity of studies on direct measurements of the facial skeleton hinders comparisons with findings in literature, but underlines the value of craniofacial dimorphism in SAHS, as shown in numerous papers ${ }^{5,7-12}$.

\section{CONCLUSION}

1. The morphometric model proposed by Kushida, Efron and Guilleminault is applicable to the selected sample in clinical practice.

2. It was not possible to establish a cutoff point to classify patients with sleep apnea-hypopnea syndrome according to severity.

\section{REFERENCES}

1. Burwell CD, Robin ED, Whaley RD, Bickelmann AG. Extreme obesity associated with alveolar hypoventilation: a Pickwickian syndrome. Am J Med 1956;2:811-8.

2. American Academy of Sleep Medicine Task Force. Sleep-related breathing disorders in adults: recommendations for syndrome definition and measurement techniques in clinical research. Sleep 1999;22(5):667-89.

3. Young T, Palta M, Dempsey J, Skatrud J, Weber S, Badr S. The occurrence of sleep-disordered breathing among middle-aged adults. N Engl J Med 1993;328:1230-5.

4. Olson LG, King MT, Hensley MJ, Saunders NA. A community study of snoring and sleep-disordered breathing. Am J Respir Care Med 1995;152:711-6.

5. Arens R, Marcus CL. Pathophysiology of upper airway obstruction: a developmental perspective. Sleep 2004;27(5):997-1019.

6. Deegan PC, McNicholas WT. Predictive value of clinical features for the obstructive sleep apnea syndrome. Eur Respir 1996;J9:117-24.

7. Friedman M, Tanyeri H, La Rosa M, Vaidyanathan K, Pieri S, Caldarell D. Clinical predictors of obstructive sleep apnea. Laryngoscope 1999;109:1901-7.

8. Schellenberg JB, Greg M, Richard JS. Physical finding and the risk for obstructive sleep apnea - The importance of oropharyngeal structures. Am J Respir Crit Care Med 2000;162:740-8.

9. Zonato AI, Bittencort LRA, Martinho FL, Santos Jr JF, Gregório LC, 
Tufik S. Association of systematic head and neck physical examination with severity of obstructive sleep apnea-hypopnea syndrome. Laryngoscope 113:973-80.

10. Lowe AA, Santamaria JD, Fleetham JA, Price C. Facial morphology and obstructive sleep apnea. Am J Orthod Dentofac Orthop 1986;90:48491.

11. Fergunson KA, Ono T, Lowe AA, Ryan F, Fleetham JA. The relationship between obesity and craniofacial structure in obstructive sleep apnea. Chest 1995;108:375-81.

12. Li KK, Powell NB, Kushida C, Robert WR, Adornato B, Guilleminault C. A comparison of Asian and white patients with obstructive sleep apnea syndrome. Laryngoscope 1999;109:1937-40.

13. Norton PG, Dunn EV. Snoring as a risk factor for disease: an epidemiological survey. Br Med J 1985;291:630-2.

14. Sox Jr. HC. Sleep apnea - a major public health problem: N Engl J Med 1993;328:1271-3.

15. Kapur V, Blough DK, Sandblom RE, Hert R, Maine JB, Sullivan SD et al. The medical cost of undiagnosed sleep apnea. Sleep 1999;22(6):74955.

16. Davies RJO, Ali NJ, Stradling JR. Neck circumference and other clinical features in the diagnosis of the obstructive sleep apnea syndrome. Thorax 1992; $47: 101-5$
17. Lattimore JD, Celermajer DS, Wilcox I. Obstructive sleep apnea and cardiovascular disease. J Am Coll Cardiol 2003;41(9):1429-37.

18. Young T, Evans L, Finn L, Palta M. Estimation of the clinically diagnosed proportion of sleep apnea syndrome on middle-aged men and women. Sleep 1997;20:705-6.

19. Viner S, Szalai JP, Hoffstein V. Are history and physical examination a good screening test for sleep apnea? Ann Intern Med 1991;115:3569.

20. Davies RJO, Ali NJ, Stradling JR. Neck circumference and other clinical features in the diagnosis of the obstructive sleep apnea syndrome. Thorax 1992;47:101-5.

21. Rauscher H., Popp W., Zwick H. Model for investigating snorers with suspected sleep apnea. Thorax 1993;48:275-9.

22. Ross SD, Sheinhait IA, Harrison KJ, Kvasz M, Connely JE, Shea S et al. Systematic review and meta-analysis of the literature regarding the diagnosis of sleep apnea. Sleep 2000;23(4):519-32.

23. Kushida CA, Bradley E, Guilleminault C. A predictive morphometric model for obstructive sleep apnea syndrome. Ann Intern Med 1997;127(8):581-7. 